\title{
Treatment of high arsenic content wastewater by a combined physical-chemical process
}

\author{
Hong-Jie Wang, ${ }^{\mathrm{a}, *}$, Wen-Xin Gong ${ }^{\mathrm{b}}$, Rui-Ping Liu ${ }^{\mathrm{b}}$, Hui-Juan Liu ${ }^{\mathrm{b}}$, Jiu-Hui $\mathbf{Q u}^{\mathrm{b}}$ \\ ${ }^{a}$ College of Environmental Science and Engineering, Beijing Forestry University, Beijing 100083, China \\ b State Key Laboratory of Environmental Aquatic Chemistry, Research Center for Eco-Environmental Sciences, Chinese Academy of Sciences, \\ Beijing 100085, China
}

\section{A R T I C L E I N F O}

\section{Article history:}

Received 29 June 2010

Received in revised form

16 November 2010

Accepted 18 November 2010

Available online 26 November 2010

\section{Keywords:}

Arsenic

Wastewater

Pre-oxidation

Co-precipitation

Adsorption

\begin{abstract}
A B S T R A C T
The performance of a novel combined process, consisting of pre-oxidation, co-precipitation, adsorption and coagulation was investigated for treatment of high arsenic content industrial wastewater. $\mathrm{KMnO}_{4}$ was used to oxidize $\mathrm{As}(\mathrm{III})$ to $\mathrm{As}(\mathrm{V})$ firstly, meanwhile the total arsenic concentration reduced about $9 \%$. Then lime and ferrous co-precipitation was performed and the arsenic concentration decreased dramatically from $423 \mathrm{mg} / \mathrm{L}$ to $6.8 \mathrm{mg} / \mathrm{L}$. Subsequent ferric and manganese binary oxide (FMBO) adsorption and polyaluminum chloride ( $\mathrm{PACl}$ ) coagulation process as a final treatment removed over $99.88 \%$ of the residual arsenic. About $5000 \mathrm{~m}^{3}$ of industrial wastewater, with average arsenic concentration of $465 \mathrm{mg} / \mathrm{L}$, was safe treated and disposed by a combined pilot-scale system. The average effluent concentration of the system was $0.008 \mathrm{mg} / \mathrm{L}$ which meet the discharge limit of $0.05 \mathrm{mg} / \mathrm{L}$, and the total removal efficiency was 99.998\%. The pilot-scale results indicated that the combined process would be advantageous and practical in treating of high arsenic content wastewater, especially in treating emergency accident of arsenic pollution.
\end{abstract}

(c) 2010 Elsevier B.V. All rights reserved.

\section{Introduction}

Most environmental arsenic problems were the result of mobilization under natural conditions. However, effluents from industries such as mining, smelting and petroleum processes had high arsenic content [1-3]. Previous literatures had provided general description of the toxicity of arsenic and health hazards, such as diseases of skin, neurological, and cardiovascular system, as well as cancer of the skin, bladder, kidney, skin, and lung, so arsenic poisoning had been a environment concern worldwide [4,5].

Many different techniques, such as ion exchange, membrane, coagulation, lime softening, precipitation and adsorption, had been developed for arsenic elimination from water [4-6]. In recent years, more attention has been paid on adsorption process for arsenic removal and a variety of adsorbent materials, such as biological materials, mineral oxides, activated carbons, or polymer resins, were developed worldwide and adsorption process was considered to be one of the most promising technologies [6]. While most of the adsorption techniques were effective for $\mathrm{As}(\mathrm{V})$ removal, but failed in case of $\mathrm{As}(\mathrm{III})$. The reason was that As(III) existed as neutral species with low affinity with conventional reagent and was more mobile. Recently, Fe-Mn-mineral materials, such as ferric and

\footnotetext{
* Corresponding author. Tel.: +86 106284 9160; fax: +86 1062849160.

E-mail address: whj_99@hotmail.com (H.-J. Wang).
}

manganese binary metal oxide (FMBO), had been investigated for oxidation of $\mathrm{As}(\mathrm{III})$ and adsorption of $\mathrm{As}(\mathrm{V})$ simultaneously [7,8]. However, for the wastewater with high concentration of arsenic ( $>400 \mathrm{mg} / \mathrm{L}$ ), any single treatment method would be inadequate to make the effluent consistent with the discharge limits (less than $0.05 \mathrm{mg} / \mathrm{L}$ ).

Pre-oxidation of $\mathrm{As}(\mathrm{III})$ was usually used to improve arsenic removal $[9,10]$. Precipitation was recognized as a useful technology for the treatment of high concentration of $\mathrm{As}(\mathrm{V})$. As long as the residual arsenic concentration was reduced to a certain level, the adsorption process would be very suitable for further treatment. Thus, a novel pilot-scale combined process, consisting of $\mathrm{KMnO}_{4}$ pre-oxidation, lime and ferrous co-precipitation, FMBO adsorption and $\mathrm{PACl}$ coagulation, was conducted in this study to safe treat and dispose the high arsenic concentration industrial wastewater.

The research was divided into two experimental phases. The first phase was laboratory studies including the optimization of pre-oxidation, co-precipitation, adsorption and coagulation, which was conducted using a six-paddle stirrer. The effects of dosage of oxidant, precipitant, adsorbent and coagulant and reaction time on arsenic removal were investigated in detail. Based on the batch experimental results, in the second phase a pilot-scale system was constructed and applied for the treatment of about $5000 \mathrm{~m}^{3}$ of industrial wastewater, with average arsenic concentration of $465 \mathrm{mg} / \mathrm{L}$. 


\section{Materials and methods}

\subsection{Materials}

Potassium permanganate $\left(\mathrm{KMnO}_{4}, 99 \%\right)$, calcium hypochlorite $\left(\mathrm{Ca}(\mathrm{ClO})_{2}, 70 \%\right)$, lime $(\mathrm{CaO}, 90 \%)$, hydrated ferrous sulfate $\left(\mathrm{FeSO}_{4} \cdot 7 \mathrm{H}_{2} \mathrm{O}, 95 \%\right)$, and $\mathrm{PACl}$ of commercial grade were utilized in the experiments. FMBO was freshly synthesized on-site by combination of the solution of $\mathrm{KMnO}_{4}$ and $\mathrm{FeSO}_{4} \cdot 7 \mathrm{H}_{2} \mathrm{O}$ stoichiometrically.

The arsenic wastewater was obtained from a sulfuric acid factory in central China. The total arsenic concentration was $450-480 \mathrm{mg} / \mathrm{L}$ and As (III) in wastewater was about $120-150 \mathrm{mg} / \mathrm{L}$. The $\mathrm{pH}$ of the wastewater was as low as 2.31-2.62. The disposal limit of arsenic was $0.05 \mathrm{mg} / \mathrm{L}$ and $\mathrm{pH}$ was in the range of 6-9.

\subsection{Batch experiments}

To investigate the behaviors of pre-oxidation, co-precipitation, adsorption and coagulation, experiments were performed in a six-paddle stirrer with $1 \mathrm{~L}$ of beakers using conventional Jar-test apparatus (MY 3000-6, Qianjiang MeiYu Instruments Ltd., China).

Appropriate amount of $\mathrm{KMnO}_{4}$ or $\mathrm{Ca}(\mathrm{ClO})_{2}$ was added into the $500 \mathrm{~mL}$ of arsenic waster water. The mixture was continuously blended for $2 \mathrm{~h}$ at $150 \mathrm{rpm}$ at room temperature $\left(25 \pm 0.5^{\circ} \mathrm{C}\right)$. At the end of the pre-oxidation, lime was added and the slurries were kept mixing for $1 \mathrm{~h}$. After settlement for another hour, different dosages of $\mathrm{FeSO}_{4} \cdot 7 \mathrm{H}_{2} \mathrm{O}$ was added into the supernatant and kept reacting with fast mixing (200 rpm) for $10 \mathrm{~s}$, slow mixing for 2 min and settlement for $30 \mathrm{~min}$. Then FMBO was added to finish the adsorption process with blending speed of $150 \mathrm{rpm}$ for $30 \mathrm{~min}$ and the suspension was settled for hours. Finally, different amounts of PACl were introduced into the system to perform coagulation. The coagulation procedure consisted of a 2 min rapid mix ( $200 \mathrm{rpm}), 15 \mathrm{~min}$ slow mix (50 rpm), and settlement for 30-120 min.

The total arsenic and As(III) concentration were determined by atomic fluorescence spectrometry (AF 610B, Ruili Instrument Ltd., Beijing, China) [11]. Mn(II) concentration was analyzed by inductively coupled plasma optical emission spectrometry (ICP-OES) (Optima 2000, Perkinelmer Co., USA). Particle size of FMBO was measured at different settling time (Malvern MasterSizer Series 2000, Malvern Instruments, UK). An Orion pH meter (Model 720 A, Thermo Orion, USA) was used to measure $\mathrm{pH}$.

\subsection{Pilot scale system description}

The pilot scale treatment procedure for high arsenic wastewater was as follows. Stock solution of $5 \% \mathrm{KMnO}_{4}$ was first added to the wastwater with dosage of $350 \mathrm{mg} / \mathrm{L}$. Four hours later, lime slurry $(\mathrm{CaO}, 10 \%)$ was directly added into the wastewater. After reacted and settled for $15 \mathrm{~h}$, the supernatant was pumped to another tank and $\mathrm{FeSO}_{4} \cdot 7 \mathrm{H}_{2} \mathrm{O}(10 \%)$ solution was added and settled for another $15 \mathrm{~h}$. Then FMBO $(200 \mathrm{mg} / \mathrm{L})$ was introduced into the system followed by gravitational settlement for $15 \mathrm{~h}$. Finally PACl $(200 \mathrm{mg} / \mathrm{L})$ was sprayed and settled till the arsenic concentration was consisted with the discharge limit. The supernatant was discharged and the method for safe treatment of solid waste, such as solidification, was investigated also (results was not shown in this paper).

\section{Results and discussion}

\subsection{Pre-oxidation by permanganate}

In the preliminary experiments, $\mathrm{KMnO}_{4}$ and $\mathrm{Ca}(\mathrm{ClO})_{2}$ were used as pre-oxidants to oxide As (III) into $\mathrm{As}(\mathrm{V})$. Results showed that $\mathrm{KMnO}_{4}$ had higher efficiency for As(III) oxidation than that of

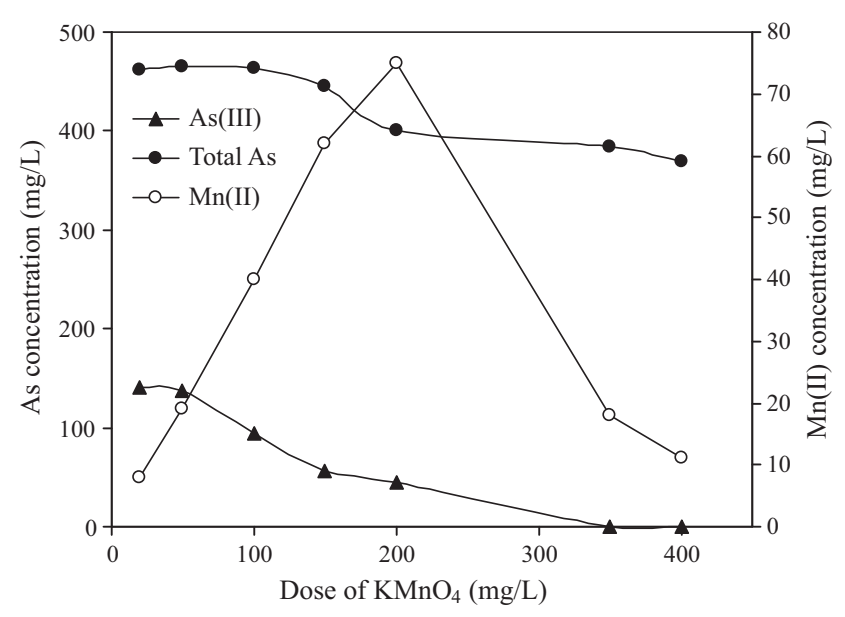

Fig. 1. Variation of total As, $\mathrm{As}(\mathrm{III})$ and $\mathrm{Mn}(\mathrm{II})$ in pre-oxidation of wastewater.

$\mathrm{Ca}(\mathrm{ClO})_{2}$. So $\mathrm{KMnO}_{4}$ was chosen as the pre-oxidant. The effect of $\mathrm{KMnO}_{4}$ concentration on As(III) oxidation was investigated and the variation of total As, $\mathrm{As}(\mathrm{III})$ and $\mathrm{Mn}(\mathrm{II})$ were shown in Fig. 1. With the addition of $\mathrm{KMnO}_{4}$, the concentration of $\mathrm{As}(\mathrm{III})$ was decreased dramatically till As(III) was turned into As(V) completely at $\mathrm{KMnO}_{4}$ dosage of $350 \mathrm{mg} / \mathrm{L}$, and the total arsenic concentration was decreased about $9 \%$.

The $\mathrm{KMnO}_{4}$ was reduced to $\mathrm{Mn}$ (II) during the oxidation of $\mathrm{As}(\mathrm{III})$. Fig. 1 showed that the $\mathrm{Mn}(\mathrm{II})$ concentration first increased with the increasing $\mathrm{KMnO}_{4}$ dosage and reached the maximum at the dosage of $200 \mathrm{mg} / \mathrm{L}$ and then decreased with further introducing of $\mathrm{KMnO}_{4}$. The possible reactions of $\mathrm{KMnO}_{4}$ and $\mathrm{As}(\mathrm{III})$ were shown as Eqs (1) $-(3)$.

$$
\begin{aligned}
& 2 \mathrm{MnO}_{4}^{-}+5 \mathrm{As}^{3+}+16 \mathrm{H}^{+} \rightarrow 5 \mathrm{As}^{5+}+2 \mathrm{Mn}^{2+}+8 \mathrm{H}_{2} \mathrm{O} \\
& 2 \mathrm{MnO}_{4}^{-}+3 \mathrm{As}^{3+}+8 \mathrm{H}^{+} \rightarrow 3 \mathrm{As}^{5+}+2 \mathrm{MnO}_{2}+4 \mathrm{H}_{2} \mathrm{O} \\
& 2 \mathrm{MnO}_{4}^{-}+3 \mathrm{Mn}^{2+}+4 \mathrm{OH}^{-} \rightarrow 5 \mathrm{MnO}_{2}+2 \mathrm{H}_{2} \mathrm{O}
\end{aligned}
$$

Eqs. (1) and (2) showed that $\mathrm{KMnO}_{4}$ could be reduced to $\mathrm{Mn}$ (II) or $\mathrm{MnO}_{2}$ in acidic solution [10]. And the reaction between $\mathrm{KMnO}_{4}$ and $\mathrm{Mn}(\mathrm{II})$, shown in Eq. (3), could also lead to the formation of $\mathrm{MnO}_{2}$. The newly formed $\mathrm{MnO}_{2}$ could adsorb arsenic, so the total As concentration decreased slightly.

\subsection{Lime-ferrous co-precipitation}

After pre-oxidation, lime was adopted as a precipitant for its formation of a hardly soluble calcium-arsenic compound [3,12,13]. Results of arsenic removal by lime precipitation were shown in Fig. 2. It can be seen that arsenic concentration decreased with the increasing dosage of lime. With $1200 \mathrm{mg} / \mathrm{L}$ of lime, arsenic concentration was reduced to about $50 \mathrm{mg} / \mathrm{L}$ and the removal efficiency achieved $90 \%$.

As shown in Fig. 2, the variation of arsenic concentration could be classified into three stages. In the first stage, lime neutralized the acidic substances in wastewater and little arsenic was removed. With the dosage of lime increased from 0 to $390 \mathrm{mg} / \mathrm{L}$, the arsenic removal efficiency was achieved at $12 \%$, but $\mathrm{pH}$ increased dramatically from 2.43 to 9.93 . In the second stage, the arsenic removal efficiency significantly increased from $12 \%$ to $71 \%$ with the addition of lime from $390 \mathrm{mg} / \mathrm{L}$ to $862 \mathrm{mg} / \mathrm{L}$, while $\mathrm{pH}$ increased to 12.58. With further addition of lime, both of $\mathrm{pH}$ and the arsenic removal efficiency increased slightly. In the second stage, most of the arsenic was removed by formation of low solubility calcium arsenates, such as $\mathrm{Ca}_{3}\left(\mathrm{AsO}_{4}\right)_{2}$. While in the third stage, with the $\mathrm{Ca} /$ As ratios increased more complicated precipitations between 


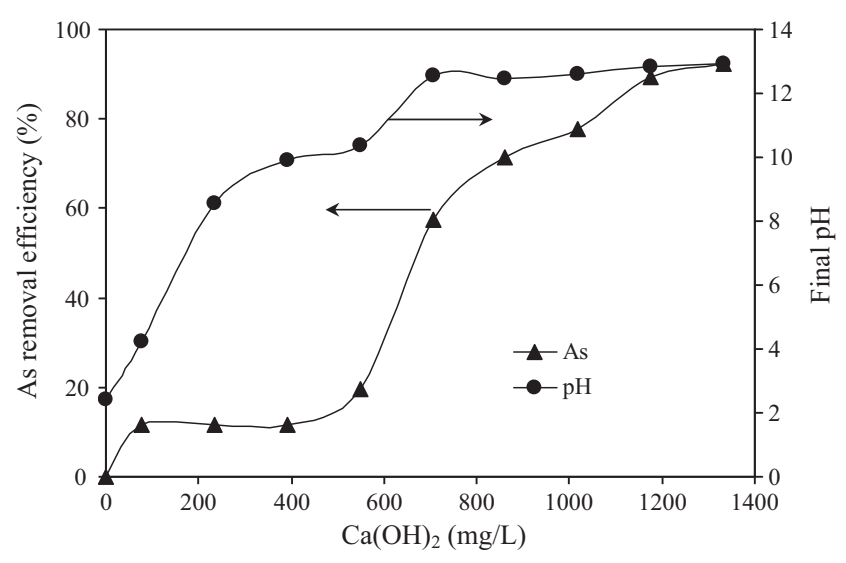

Fig. 2. Arsenic removal by lime precipitation.

arsenic and calcium formed $[14,15]$. Although the lime precipitation was effective, the solubility of $\mathrm{Ca}_{3}\left(\mathrm{AsO}_{4}\right)_{2}$ was $130 \mathrm{mg} / \mathrm{L}$, the calculated arsenic concentration was as high as $48 \mathrm{mg} / \mathrm{L}$. In above experiment the arsenic concentration of the effluent was still as high as $50 \mathrm{mg} / \mathrm{L}$. To reduce the arsenic concentration even further, by formation of other insoluble compounds, the addition of iron salts was investigated in this study.

Fig. 3 showed the arsenic removal efficiency by ferrous ion coprecipitation. With the addition of $\mathrm{FeSO}_{4} \cdot 7 \mathrm{H}_{2} \mathrm{O}$ and increase of settle time, the arsenic concentration of supernatant decreased. With the addition of $180 \mathrm{mg} / \mathrm{L}$ of $\mathrm{FeSO}_{4} \cdot 7 \mathrm{H}_{2} \mathrm{O}$, the arsenic concentration reached $7.98 \mathrm{mg} / \mathrm{L}, 3.75 \mathrm{mg} / \mathrm{L}$ and $0.21 \mathrm{mg} / \mathrm{L}$ when the suspension was settled for $2 \mathrm{~h}, 5 \mathrm{~h}$ and $12 \mathrm{~h}$, respectively. There was no significant increase in arsenic removal efficiency with excessive addition of ferrous ion, so the optimal dose of $\mathrm{FeSO}_{4} \cdot 7 \mathrm{H}_{2} \mathrm{O}$ was $180 \mathrm{mg} / \mathrm{L}$.

\subsection{Adsorption by FMBO combined with coagulation}

After pre-oxidation and co-precipitation, the arsenic concentration was reduced to less than $8 \mathrm{mg} / \mathrm{L}$. Then adsorption was more suitable for further treatment. FMBO, the novel adsorbent, was online synthesized and added into the wastewater. The results were shown in Fig. 4.

With the addition of FMBO from $20 \mathrm{mg} / \mathrm{L}$ to $300 \mathrm{mg} / \mathrm{L}$, the residual arsenic concentration decreased continually. And the settle time could also affect the results. The arsenic removal efficiency increased quickly till the dose of FMBO reached $150 \mathrm{mg} / \mathrm{L}$ and the residual arsenic concentration was reduced to $0.23 \mathrm{mg} / \mathrm{L}, 0.19 \mathrm{mg} / \mathrm{L}$ after settled for $2 \mathrm{~h}$ and $12 \mathrm{~h}$, respectively. Then the suspension was

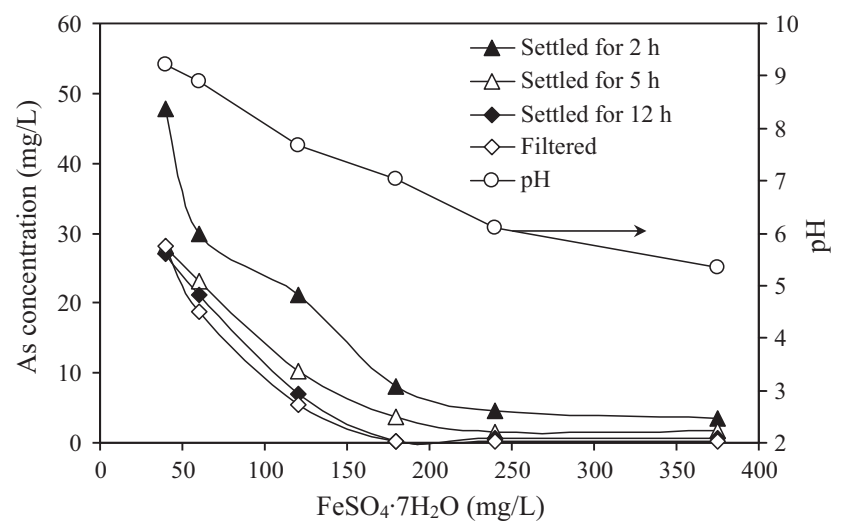

Fig. 3. Variation of arsenic concentration in ferric ion co-precipitation.

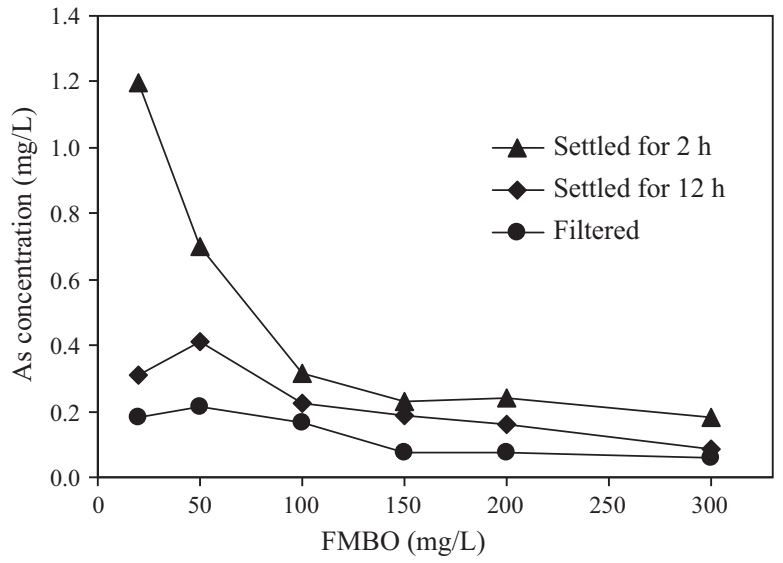

Fig. 4. Variation of arsenic concentration with dose of FMBO.

filtered by $0.45 \mu \mathrm{m}$ Teflon film, the residual arsenic concentration of the filtrate was just as low as $0.08 \mathrm{mg} / \mathrm{L}$. Further increase of FMBO just induced slight decrease of arsenic concentration and the residual arsenic concentration of the filtrate maintained at $0.08 \mathrm{mg} / \mathrm{L}$.

With the addition of $150 \mathrm{mg} / \mathrm{L}$ of FMBO, the residual arsenic concentration was detected before and after filtered by $0.45 \mu \mathrm{m}$ Teflon film according to the settle time. And the results were shown in Fig. 5. It showed that there was no significant variation of the residual arsenic concentration after the suspension settled for over $30 \mathrm{~min}$ and filtered, while the total arsenic concentration decreased continually with the settle time. It was revealed that the adsorption process completed quickly but the separation process was very slow due to the colloid character of FMBO. Then the particle size of FMBO, which would influence the arsenic removal efficieny, was investigated further.

The mean diameter of newly formed FMBO was about $112 \mu \mathrm{m}$ and after settled for $2 \mathrm{~h}$ the mean diameter of FMBO in supernatant was reduced to $19.5 \mu \mathrm{m}$. Because of the strong affinity of the colloid FMBO with arsenic, the residual arsenic concentration remained much higher than that of the filtrate. The smaller was the particle size, the slower was the separation process. So in this study, PACl was used as a coagulant for the colloid FMBO particles separation. Results in Fig. 6 showed that with the addition of PACl the residual arsenic concentration decreased dramatically. With $100 \mathrm{mg} / \mathrm{L}$ of $\mathrm{PACl}$ and $2 \mathrm{~h}$ settlement, the arsenic concentration reduced to less than $0.05 \mathrm{mg} / \mathrm{L}$ which was in accordance with the disposal limits. And when PACl was increased to $150 \mathrm{mg} / \mathrm{L}$ the arsenic concentration could also reduce to less than $0.05 \mathrm{mg} / \mathrm{L}$ just after $30 \mathrm{~min}$

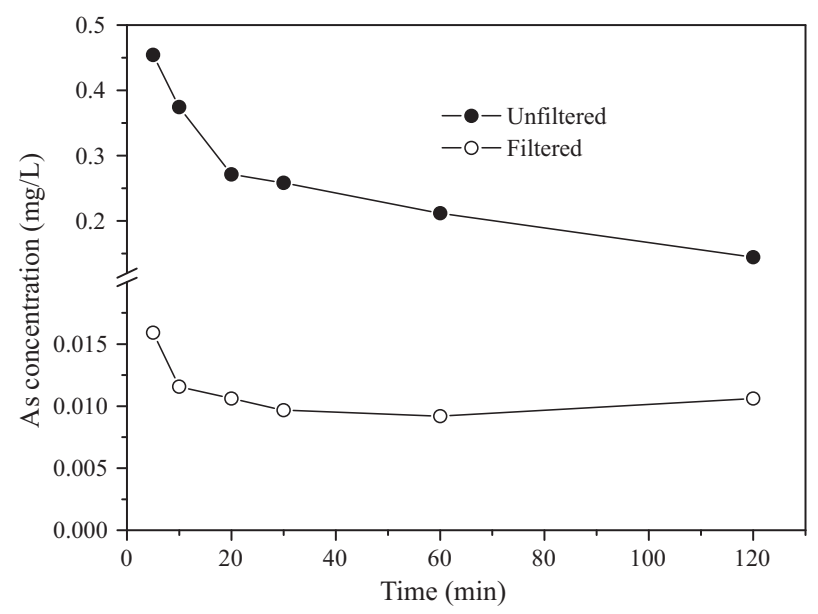

Fig. 5. Effects of settling time on arsenic removal by FMBO (dosage: $150 \mathrm{mg} / \mathrm{L}$ ). 


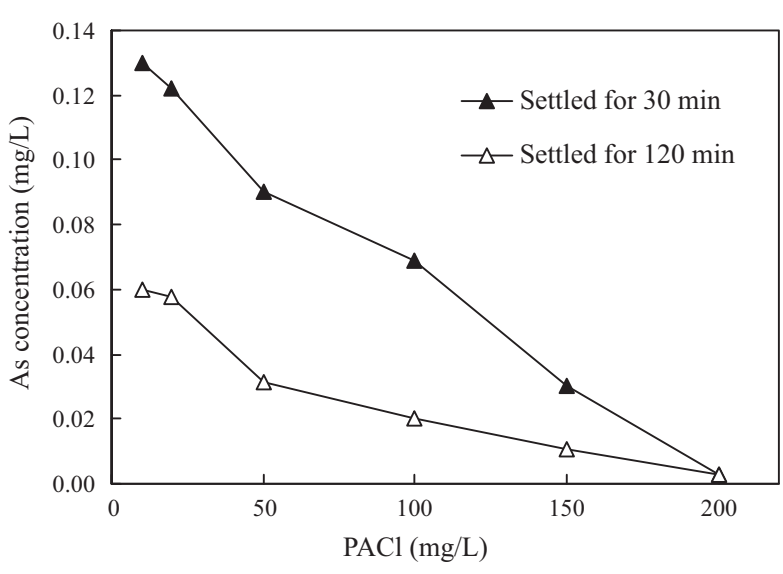

Fig. 6. Further removal of arsenic by flocculation of PACl.

settlement. So the dose of PACl and the settle time could adjust flexibly according to the real situation.

\subsection{Pilot scale treatment and economic evaluation of the combined process}

Batch test showed that the combined process, consisting of $\mathrm{KMnO}_{4}$ pre-oxidation, lime and ferrous co-precipitation, FMBO adsorption and PACl coagulation and flocculation, could effectively reduce the arsenic concentration from $462 \mathrm{mg} / \mathrm{L}$ to less than $0.05 \mathrm{mg} / \mathrm{L}$. The pilot scale treatment for the high arsenic content wastewater was conducted with the combined process. The main parameters of the system, which based on the laboratory results but had a little change to adapt to the practical application, were as follows: $\mathrm{KMnO}_{4}, 350 \mathrm{mg} / \mathrm{L}$, hydraulic retention time (HRT), $4 \mathrm{~h}$; Lime, $1 \mathrm{~g} / \mathrm{L}, \mathrm{HRT}, 15 \mathrm{~h} ; \mathrm{FeSO}_{4} \cdot 7 \mathrm{H}_{2} \mathrm{O}, 200 \mathrm{mg} / \mathrm{L}, \mathrm{HRT}, 15 \mathrm{~h} ; \mathrm{FMBO}, 200 \mathrm{mg} / \mathrm{L}$, HRT, $15 \mathrm{~h}$; PACl, $200 \mathrm{mg} / \mathrm{L}, \mathrm{HRT}, 8 \mathrm{~h}$. The pilot scale treatment results of the combined process were shown in Table 1.

Chemical pre-oxidation and co-precipitation process proved to be effective in the removal of arsenic (removal efficiency higher than $98 \%$ ) and subsequent adsorption and coagulation process as a final treatment efficiently removed the residual arsenic. The average total removal efficiency of arsenic in the pilot-scale combined technology was $99.998 \%$ which was giving an average effluent concentration of $0.008 \mathrm{mg} / \mathrm{L}$, consistent with the disposal limit $(<0.05 \mathrm{mg} / \mathrm{L})$.

Table 2 showed the evaluation of economic performance of the combined process. Due to the high price of the $\mathrm{KMnO}_{4}$, the cost of pre-oxidation took over $60 \%$ of the total cost. Although most of the arsenic was removed by lime and ferrous co-precipitation process, the cost of the lime and ferrous ion co-precipitation took only $2.7 \%$ of the total cost. It was seemed that FMBO adsorption process was a little expensive. But the FMBO adsorption and PACl coagula-

Table 1

Pilot scale treatment of high arsenic wastewater.

\begin{tabular}{llll}
\hline Process & $\begin{array}{l}\text { As } \\
\text { concentration } \\
(\mathrm{mg} / \mathrm{L})\end{array}$ & $\begin{array}{l}\text { Removal } \\
\text { efficiency per } \\
\text { process (\%) }\end{array}$ & \\
\cline { 2 - 4 } & Range & Average & \\
\hline Raw water & $450-480$ & 465 & \\
Pre-oxidation & $426-430$ & 423 & 9.03 \\
Lime co-precipitation & $18-26$ & 24 & 94.33 \\
Fe $^{2+}$ co-precipitation & $6-7.6$ & 6.8 & 71.67 \\
FMBO+PACl & $0.002-0.013$ & 0.008 & 99.88 \\
Total removal efficiency (\%) & & & 99.998 \\
\hline
\end{tabular}

Table 2

Economic evaluation of pilot scale combined process.

\begin{tabular}{lcl}
\hline Chemical reagent and dosages & Price $(¥ / \mathrm{kg})$ & Process $\operatorname{Cost}\left(¥ / \mathrm{m}^{3}\right)$ \\
\hline $\mathrm{KMnO}_{4}, 0.30 \mathrm{~kg} / \mathrm{m}^{3}$ & 12.00 & 3.60 \\
$\mathrm{Lime}, 1 \mathrm{~kg} / \mathrm{m}^{3}$ & 0.10 & 0.10 \\
$\mathrm{FeSO}_{4} \cdot 7 \mathrm{H}_{2} \mathrm{O}, 0.2 \mathrm{~kg} / \mathrm{m}^{3}$ & 0.30 & 0.06 \\
$\mathrm{FMBO}, 0.2 \mathrm{~kg} / \mathrm{m}^{3}$ & 10.00 & 2.00 \\
$\mathrm{PACl}, 0.2 \mathrm{~kg} / \mathrm{m}^{3}$ & 1.00 & 0.20 \\
& & \\
Total cost & & 5.96 \\
\hline
\end{tabular}

tion and flocculation process could effectively reduce the arsenic concentration from several $\mathrm{mg} / \mathrm{L}$ to less than $0.05 \mathrm{mg} / \mathrm{L}$. It was indicated that the combined system was very practical in treating emergency.

\section{Conclusions}

High arsenic acidic wastewater with average concentration of $465 \mathrm{mg} / \mathrm{L}$ was effectively and safe treated and disposed by the combined process of pre-oxidation, lime and ferrous precipitation, FMBO adsorption and PACl flocculation. Pre-oxidation was necessary because of $120-150 \mathrm{mg} / \mathrm{L}$ of $\mathrm{As}(\mathrm{III})$ in the acidic wastewater. $\mathrm{KMnO}_{4}$ could completely oxidize As(III) and the byproduct of $\mathrm{MnO}_{2}$ could also adsorb arsenic. The removal efficiency of pre-oxidation was about $9 \%$. In lime and ferrous co-precipitation process a series of hardly soluble compounds formed and settled. The arsenic concentration was reduced from $423 \mathrm{mg} / \mathrm{L}$ to about $6.8 \mathrm{mg} / \mathrm{L}$. FMBO was used to further remove arsenic by adsorption and the residual arsenic could be nearly completely adsorbed by FMBO. But it was hard for FMBO to settle down thoroughly due to its colloid characters and the $\mathrm{PACl}$ coagulation was necessary in practical. About $5000 \mathrm{~m}^{3}$ of industrial wastewater, with average arsenic concentration of $465 \mathrm{mg} / \mathrm{L}$, was effectively, economically and safe treated and disposed. The arsenic concentration of the final effluent was less than $0.013 \mathrm{mg} / \mathrm{L}$. The current results and the economic evaluation suggested that the combined process could be advantageous and feasible for the treatment of high concentration of arsenic wastewater.

\section{Acknowledgments}

This work was supported by the National High-tech R\&D Programme of China (no. 2009AA062905) and the Technology Innovation Programme of Beijing Forestry University of China (no. TD2010-5).

\section{References}

[1] S. Song, A. Lopez-Valdivieso, D.J. Hernandez-Campos, C. Peng, M.G. MonroyFernandez, I. Razo-Soto, Arsenic removal from high-arsenic water by enhanced coagulation with ferric ions and coarse calcite, Water Res. 40 (2006) 364372.

[2] C. Huang, J.R. Pan, M. Lee, S. Yen, Treatment of high-level arsenic-containing wastewater by fluidized bed crystallization process, J. Chem. Technol. Biotechnol. 82 (2007) 289-294.

[3] D. Kalderis, E. Tsolaki, C. Antoniou, E. Diamadopoulos, Characterization and treatment of wastewater produced during the hydro-metallurgical extraction of germanium from fly ash, Desalination 230 (2008) 162-174.

[4] M. Vaclavikova, G.P. Gallios, S. Hredzak, S. Jakabsky, Removal of arsenic from water streams: an overview of available techniques, Clean Technol. Environ. Policy 10 (2008) 89-95.

[5] L.C. Roberts, S.J. Hug, T. Ruettimann, A.W. Khan, M.T. Rahman, Arsenic remova with iron (II) and iron (III) in waters with high silicate and phosphate concentrations, Environ. Sci. Technol. 38 (2004) 307-315.

[6] D. Mohan, C.U. Pittman Jr., Arsenic removal from water/wastewater using adsorbents-a critical review, J. Hazard. Mater. 142 (2007) 1-53.

[7] G.S. Zhang, J.H. Qu, H.J. Liu, R.P. Liu, G.T. Li, Removal mechanism of As (III) by a novel Fe-Mn binary oxide adsorbent: oxidation and sorption, Environ. Sci. Technol. 41 (2007) 4613-4619. 
[8] G.S. Zhang, J.H. Qu, H.J. Liu, R.P. Liu, R.C. Wu, Preparation and evaluation of a novel Fe-Mn binary oxide adsorbent for effective arsenite removal, Water Res. 41 (2007) 1921-1928.

[9] M.J. Kim, J. Nriagu, Oxidation of arsenite in groundwater using ozone and oxygen, Sci. Total Environ. 247 (2000) 71-79.

[10] N. Li, M.H. Fan, J. Van Leeuwen, H.Q. Saha Basudeb, C.P. Yang, Huang, Oxidation of As(III) by potassium permanganate, J. Environ. Sci. (China) 19 (2007) $783-786$.

[11] F.F. Chang, J.H. Qu, H.J. Liu, R.P. Liu, X. Zhao, Fe-Mn binary oxide incorporated into diatomite as an adsorbent for arsenite removal: preparation and evaluation, J. Colloid Interface Sci. 338 (2009) 353-358.
[12] V. Dutré, C. Vandecasteele, Solidification/stabilisation of hazardous arsenic containing waste from a copper refining process, J. Hazard. Mater. 40 (1995) $55-68$.

[13] B. Doušová, D. Koloušek, F. Kovanda, V. Machovič, M. Novotná, Removal of As(V) species from extremely contaminated mining water, Appl. Clay Sci. 28 (2005) 31-42.

[14] Y.N. Zhu, H. Zhang, Y.P. Liang, H.L. Liu, X.H. Zhang, Dependence of solubility and stability of calciumarsenates on $\mathrm{pH}$ value, Acta Scientiae Circumstantiae (in Chinese) 25 (2005) 1652-1660.

[15] J.V. Bothe, P.W. Brown, Arsenic immobilization by calcium arsenate formation, Environ. Sci. Technol. 33 (1999) 3806-3811. 